\title{
Indicadores microbiológicos como parâmetro de qualidade da água de dois corpos hídricos na ARIE Floresta da Cicuta - RJ
}

Victor M aximiliano R eis T ebaldi

Professor D outor, C entro Universitário de B arra M ansa, UBM

Silvério Pereira

$G$ raduando em B iologia.

C entro Universitário de B arra M ansa, UBM

E laine $M$ aria Pizol Sanches

B ióloga. D epartamento de L aboratórios M ultidisciplinares.

C entro Universitário de B arra M ansa, UBM

Sandro L eonardo A Ives

A nalista A mbiental. Instituto C hico M endes da B iodiversidade - IC M R io 


\section{Resumo}

0 trabalho visou avaliar a qualidade da água de dois corpos hídricos na A RIE Floresta da Cicuta-RJ. Foram amostrados três pontos do rio B randão e cinco pontos do córrego Á guas Frias. Foi empregada a técnica de plaqueamento em profundidade para a contagem de microrganismos heterotróficos totais e a técnica do $N$ úmero $M$ ais P rovável (N M P) para enumeração de coliformes. Os resultados evidenciaram a contaminação dos corpos hídricos por coliformes totais e termotolerantes. Foi confirmada a presença de $\mathrm{E}$. coli em quatro pontos do córrego Á guas F rias. As contagens de microrganismos heterotróficos revelaram valores de: máximo $1,6 \times 10^{7} \mathrm{UFC} / \mathrm{mL}$ e mínimo de $8,0 \times 10^{2}$ $U F C / m L$. Ressalta-se a necessidade de ações voltadas para a educação ambiental, evitando os despejos de resíduos não tratados. Salienta-se a importância da adoção de políticas públicas das cidades para tratamento de esgotos e a importância do monitoramento frequente da qualidade da água nesta U nidade de C onservação.

Palavras-chave: Á gua. Recursos naturais. Contaminação. Coliformes.

\section{Abstract}

The aim of this study was to evaluate the quality of water from two water bodies at ARIE Forest of Cicuta-RJ. W ere sampled three points of the Brandão river and five points of the Á guas F rias stream. The depth plating technique was used to count total heterotrophic microorganisms whereas the M ost Probable N umber (M PN) technique was utilized to enumerate coliforms. The results evidenced the contamination of the water bodies by total and thermotolerant coliforms. The presence of $E$. coli was confirmed in four points of the Águas Frias stream. The counting of heterotrophic microorganisms revealed maximum values of $1.6 \times 10^{7} \mathrm{CFU} / \mathrm{mL}$ and minimum of $8.0 \times 10^{2} \mathrm{CFU} / \mathrm{mL}$. E mphasis is placed on the need for actions focused on environmental education, against the dumping of untreated waste. It is highlighted the importance of the adoption of public policies by cities for sewage treatment and the importance of frequent monitoring of water quality in this $\mathrm{C}$ onservation U nit.

K ey words: W ater. $N$ atural resources. Contamination. C oliforms. 


\section{Introdução}

A água doce é um recurso finito e indispensável à manutenção da vida na T erra e vem sendo alvo de discussões sobre a poluição, escassez e suas formas de uso. É um dos elementos mais importantes da biosfera para a sobrevivência da espécie humana, bem como de toda a vida na T erra (CUN H A et al., 2010).

O crescimento urbano e indiscriminado próximo a mananciais e rios causa a remoção florestal, despejo de lixos e esgotos e impermeabilização do solo, tornando a qualidade da água desse manancial comprometida pela presença de coliformes, e outros contaminantes provenientes de resíduos urbanos e industriais (ANDREOLI et al., 2000).

A degradação da alta carga de matéria orgânica trazida pelo esgoto e lixiviação de solos acarreta, na depleção de oxigênio da água, aumento da turbidez, levando à redução da fotossíntese e produção primária, aumento da concentração de alguns micropoluentes e da concentração de metais e microrganismos patogênicos (PA U L A et al., 2013).

Indicadores microbiológicos têm sido utilizados mundialmente para verificar a contaminação de corpos hídricos por resíduos humanos. Tipicamente, são utilizados organismos que são encontrados em elevadas concentrações em fezes humanas. Os indicadores geralmente utilizados incluem coliformes totais, coliformes fecais, E scherichia coli e enterococci (SH IBA T A et al., 2004).

O escoamento superficial, durante o período de chuva, é o fator que mais contribui para a mudança da qualidade microbiológica da água. A presença de coliformes nas amostras de água de mananciais, segundo A maral et al. (2003), tem relação direta com a presença de chuva, devido ao arraste de excretas humanos e animais. A ausência de tratamento favorece 0 alto nível de contaminação.

As bacias hidrográficas constituem ecossistemas adequados para avaliação dos impactos causados pela atividade antrópica, os quais acarretam riscos ao equilíbrio e a manutenção da quantidade e qualidade da água (T O RRE S et al., 2009).

No Estado do Rio de Janeiro, os remanescentes florestais constituem porção estratégica ao longo da zona de ocorrência da Floresta Atlântica, pois concentram elevada riqueza de espécies, apresentando várias áreas reconhecidas como de "Extrema Importância Biológica” (ROCHA et al., 2003). 
Inserida neste contexto está a Floresta da Cicuta, localizada entre os municípios de Barra $M$ ansa-RJ e V olta R edonda-RJ e cortada pelo Rio Brandão, um dos afluentes do Rio Paraíba do Sul. A Unidade de Conservação (UC) também é banhada pelo córrego Águas Frias, e ambos os rios servem para dessedentação animal além de oferecerem proteção natural contra incêndios. 0 Brandão é um rio quase totalmente urbano e ao longo de seu curso recebe despejo de esgoto doméstico de vários bairros. D essa forma, o rio chega à F loresta com alta carga de poluentes.

D iante do exposto, o trabalho visou avaliar a qualidade da água de dois corpos hídricos situados na Á rea de Relevante Interesse E cológico (A RIE ) Floresta da Cicuta com base nos indicadores microbiológicos.

\section{Metodologia}

\section{ÁREA DE ESTUDO E DELINEAMENTO AMOSTRAL}

Situada entre as Serras do $M$ ar e da $M$ antiqueira, abrangendo parte dos municípios de Barra M ansa e Volta Redonda, na região do M édio Vale do Paraíba do Sul, Rio de Janeiro, a Floresta da $\mathrm{C}$ icuta encontra-se atualmente protegida pelo decreto №. 90.792 de 9 de janeiro de 1985, estando enquadrada na categoria de A RIE. E sta U nidade de Conservação localiza-se entre as coordenadas de $22^{\circ} 24^{\prime}$ e $22^{\circ} 38^{\prime}$ Sul e $44^{\circ}$ 09' e 44 20' Oeste, compreendendo 131 ha. As altitudes variam entre 300 a $500 \mathrm{~m}$ (M O N SORES et al.1982). N a classificação de Köppen, o clima local é mesotérmico ( $\mathrm{C}$ wa), com inverno seco e verão quente e chuvoso, com elevados índices de umidade. As temperaturas médias anuais variam entre $17^{\circ} \mathrm{C}$ (julho) e $24^{\circ} \mathrm{C}$ (fevereiro) e as precipitações entre 1.000 a 1.600 mm/ano (M O N SO RE S et al., 1982).

\section{PONTOSDE COLETA}

Foram selecionados três pontos para coleta de água ao longo do rio $B$ randão ( $B D 1, B D 2$ e BD 3) e cinco pontos de coleta, ao longo do córrego Á guas Frias (AF 1, AF 2, AF3, AF 4 e AF5) (Figura 1). As coordenadas geográficas, de acordo com cada ponto, são: P. 73: $22^{\circ} 33^{\prime}$ e 20,9" sul 44 05' e 14,3" oeste (BD1); P. 74: $22^{\circ} 32$ ' e 36,4"

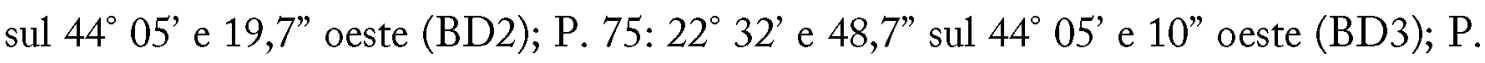


327: $22^{\circ} 33^{\prime}$ e $0,0^{\circ}$ sul $44^{\circ} 05^{\prime} 33,8^{\prime \prime}$ oeste (AF1); P. 328: $22^{\circ} 32^{\prime}$ e $53^{\circ}$ sul $44^{\circ} 05^{\prime} 31,6^{\prime \prime}$ oeste (AF2); P. 329: $22^{\circ} 32^{\prime}$ e $50,6^{\circ}$ sul $44^{\circ} 05^{\prime} 25,1^{\prime \prime}$ oeste (AF3); P. 330: $22^{\circ} 33^{\prime}$ e $52,6^{\circ}$

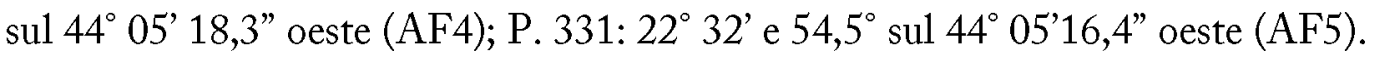

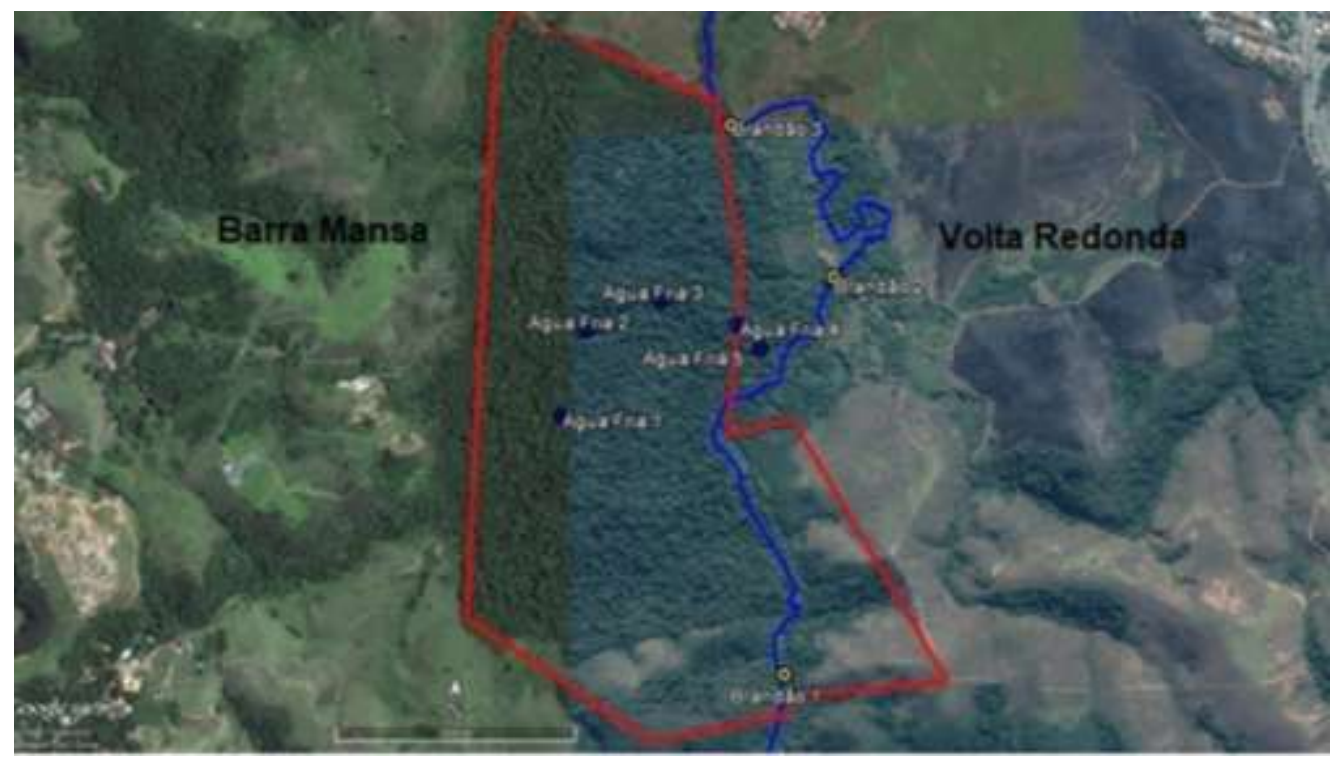

Figura 1. Vista aérea da A RIE Floresta da C icuta destacando os pontos de coleta de água

\section{COLETA DASAMOSTRAS}

As coletas foram realizadas com a autorização para atividades com finalidade científica expedida pelo Instituto Chico M endes de Conservação da Biodiversidade (ICM Bio), sob o número: 57573.

As amostras foram coletadas em frascos estéreis, sendo imersos contra a correnteza até a profundidade de aproximadamente $20 \mathrm{~cm}$, de modo a coletar um volume de água superior a $100 \mathrm{~mL}$, deixando um espaço livre no frasco para agitação antes de proceder as análises.

A pós identificação das amostras, as mesmas foram acondicionadas em recipiente térmico e imediatamente conduzidas ao Laboratório de Microbiologia do Centro Universitário de Barra M ansa para realização das análises. 


\section{CONTAGEM DE MICRORGANISMOSHETEROTRÓFICOSTOTAIS}

A s amostras coletadas tiveram seus frascos homogeneizados com 25 movimentos suaves. Em seguida, foi retirado $1 \mathrm{~mL}$ da amostra e transferido para série de tubos, contendo $9 \mathrm{~mL}$ de Tampão Fosfato com Cloreto de M agnésio, obtendo-se diluições seriadas decimais até $10^{-5}$.

Foi empregada a técnica de plaqueamento em profundidade (pour plate), transferindo-se alíquotas de $1 \mathrm{~mL}$ das diluições $10^{-1}$ a $10^{-4}$ em placas de Petri estéreis. Em seguida, foram adicionados $\sim 20 \mathrm{~mL}$ de Ágar Padrão para Contagem (PCA), previamente fundido e resfriado a 44-46으. E m seguida, o inóculo foi misturado com 0 meio de cultura, por meio de movimentos circulares suaves, em forma de "8". Após solidificação do meio, as placas foram incubadas a $37^{\circ} \mathrm{C} / 24 \mathrm{~h}$, com posterior contagem de unidades formadoras de colônias (UFC). 0 plaqueamento de todas as amostras foi conduzido em triplicata. A s análises foram realizadas de acordo com Silva et al. (2010).

\section{ENUMERAÇÃO DE COLIFORMESTOTAISE TERMOTOLERANTES}

As amostras foram homogeneizadas por agitação, invertendo o frasco 25 vezes em ângulo de $45^{\circ}$. A líquotas de $1 \mathrm{~mL}$ das amostras de água foram transferidas para tubos contendo $9 \mathrm{~mL}$ de Tampão Fosfato com Cloreto de $M$ agnésio, realizando-se diluições seriadas até $10^{-5}$. Em seguida, alíquotas de $1 \mathrm{~mL}$ das diluições foram transferidas para séries de três tubos de C aldo L auril Sulfato T riptose (LST) em dupla concentração e incubados a $35^{\circ} \mathrm{C} / 24-48 \mathrm{~h}$. Foram considerados positivos os testes que apresentaram produção de gás nos tubos de D urham. A partir dos tubos positivos de caldo LST, foram transferidas alíquotas com alça de semeadura para tubos contendo Caldo Bile Verde Brilhante (VB) e Caldo Escherichia coli (EC), para a realização de testes confirmativos para coliformes totais e termotolerantes, respectivamente. $O \mathrm{~s}$ tubos contendo Caldo VB foram incubados a $35^{\circ} \mathrm{C} / 24-48 \mathrm{~h}$ e $\mathrm{C}$ aldo EC a $45^{\circ} \mathrm{C} / 24 \mathrm{~h}$. Os tubos de EC positivos para coliformes termotolerantes foram suspeitos da presença de E . coli sendo então confirmada sua presença por meio de provas bioquímicas. 
Para confirmação de Escherichia coli, uma alçada de cada tubo de caldo EC positivo foi estriada em Ágar Eosina Azul de M etileno (EM B). As placas foram incubadas a $35 \circ \mathrm{C} / 24 \mathrm{~h}$. D as placas que apresentaram crescimento de colônias típicas de E . coli (nucleadas com o centro preto com ou sem brilho verde metálico) foram coletadas e transferidas colônias isoladas para tubos contendo Á gar Tripticase de Soja (TSA) inclinado, incubando-oS a $35^{\circ} \mathrm{C} / 24 \mathrm{~h}$. A pós o crescimento no Á gar T SA . A confirmação de $E$. coli foi realizada por meio de testes bioquímicos IM VIC (indol; vermelho de metila; V oges-P roskauer; citrato).

\section{Resultados e Discussão}

$\mathrm{N}$ a T abela 1 estão expressos os resultados da quantificação de microrganismos heterotróficos totais, coliformes totais $\left(35^{\circ} \mathrm{C}\right)$ e coliformes termotolerantes $\left(45^{\circ} \mathrm{C}\right)$ nas amostras de água do rio Brandão e córrego Á guas F rias.

T abela 1. R esultados das contagens de microrganismos heterotróficos totais, coliformes totais e termotolerantes em amostras de água coletadas na A R IE F loresta da Cicuta

\begin{tabular}{lccc}
\hline & $\begin{array}{c}\text { Contagem de } \\
\text { Heterotróficos } \\
\text { totais } \\
\text { (UFC/mL) }\end{array}$ & $\begin{array}{c}\text { Coliformes } \\
\text { Totais } \\
\text { (NMP/100 mL) }\end{array}$ & $\begin{array}{c}\text { Coliformes } \\
\text { Termotolerantes } \\
\text { (NMP/100 mL) }\end{array}$ \\
\hline BD1 & $1,0 \times 10^{6}$ & $4,5 \times 10^{2}$ & $4,5 \times 10^{2}$ \\
BD2 & $7,6 \times 10^{4}$ & $7,8 \times 10^{2}$ & $7,8 \times 10^{2}$ \\
BD3 & $1,6 \times 10^{7}$ & $4,0 \times 10^{2}$ & $4,0 \times 10^{2}$ \\
AF1 & $2,0 \times 10^{3}$ & $1,1 \times 10^{3}$ & $1,1 \times 10^{3}$ \\
AF2 & $8,0 \times 10^{2}$ & $1,1 \times 10^{3}$ & $1,1 \times 10^{3}$ \\
AF3 & $1,0 \times 10^{5}$ & $2,4 \times 10^{3}$ & $1,4 \times 10^{3}$ \\
AF4 & $5,0 \times 10^{3}$ & $1,4 \times 10^{3}$ & $6,8 \times 10^{2}$ \\
AF5 & $7,9 \times 10^{4}$ & $1,4 \times 10^{3}$ & $1,4 \times 10^{3}$ \\
\hline Nota: Amostras com números antecedidos pelas letras BD referem-se aos pontos de coleta \\
do rio Brandão, amostras com números antecedidos pelas letras AF referem-se aos pontos \\
de coleta do córrego Águas Frias
\end{tabular}

Os resultados encontrados neste trabalho revelaram valores para contagem de coliformes termotolerantes que alcançaram $1000 \mathrm{NMP} / 100 \mathrm{~mL}$ em algumas das 
amostras analisadas. D e acordo com a Resolução do CO N A M A n 357, de 17 de março de 2005, a água analisada na A RIE Floresta da C icuta é classificada como água de classe especial. N o que concerne aos parâmetros microbiológicos de qualidade, a legislação não estipula valores para coliformes fecais para esta classe. N o entanto, essa água é utilizada para dessedentação de animais no interior da Floresta e é importante para a conservação de comunidades aquáticas e manutenção do equilíbrio ecológico. Dessa forma, é importante que sua qualidade microbiológica seja satisfatória.

O principal rio que corta a ARIE, o rio Brandão, está poluído e assoreado, e ocorre frequentemente carreamento de lixo e chorume, devido ao A terro Sanitário de Volta Redonda estar localizado a montante da UC. Esse rio, parte da beleza cênica local, já chega à ARIE com altos índices de contaminação por efluentes domésticos e lixão. Foi encontrado, na área da represa, inclusive material de lixo hospitalar, além de toda ordem de material, tais como pneus e garrafas de plástico, transportados em épocas de alta vazão. A UC também é banhada pelo córrego Á guas Frias, e outros tributários que servem para a dessedentação dos animais e oferecem proteção natural contra incêndios (BRA SIL , 2016).

De acordo com os resultados encontrados, pode-se constatar que despejos de esgotos são lançados em al guns pontos dos corpos hídricos, estudados antes da passagem dos mesmos pela ARIE, tornando essa água contaminada por microrganismos. Segundo C unha et al. (2010), uma forte alteração dos níveis de concentração de coliformes fecais em alguns corpos d'água podem ser observados nas áreas de drenagem próximas e intercortadas por zonas urbanas e periurbanas.

M aiores valores para contagem de microrganismos heterotróficos totais foram observados nas águas do rio Brandão $\left(1,6 \times 10^{7} \mathrm{UFC} / \mathrm{mL}\right)$ quando comparados com os valores encontrados nas águas do córrego Á guas Frias (valor máximo de 7,9 x 104 UFC/mL ), não existindo na legislação vigente um valor aceitável para esta categoria de microrganismos. Vale ressaltar que nas águas onde 0 índice de bactérias heterotróficas totais foi mais alto, a contagem de coliformes foi menor.

M esmo que a maioria das bactérias heterotróficas da água não seja considerada patogênica, é importante que sua densidade seja mantida sob controle, pois densidades muito elevadas dessas bactérias na água podem causar riscos à saúde. Algumas dessas bactérias podem atuar como patógenos oportunistas, deteriorantes da qualidade da água; ocasionando odores e sabores desagradáveis e produzindo limo e películas, e influência 
inibidora de alguns microrganismos; pois quando presentes em número elevado podem impedir a detecção de coliformes (FIL H O e DIAS, 2008).

Segundo a Portaria no 1.469 , de 29 de dezembro de 2000 do M inistério da Saúde, a contagem de bactérias heterotróficas totais segue pela determinação da densidade de bactérias que são capazes de produzir unidades formadoras de colônias (UFC), na presença de compostos orgânicos contidos em meio de cultura apropriado, sob condições pré-estabelecidas de incubação: $35,0, \pm 0,5^{\circ} \mathrm{C}$ por 48 horas (BRASIL, 2001).

$\mathrm{Na}$ Tabela 2 estão expressos os resultados das provas bioquímicas para a confirmação da presença ou ausência da E . coli nas amostras de água analisadas.

T abela 2. Resultados das provas bioquímicas para confirmação da presença de E scherichia coli nas amostras de água analisadas

\begin{tabular}{cc}
\hline Amostras & Escherichia coli \\
\hline BD1 & Ausência \\
BD2 & Ausência \\
BD3 & Ausência \\
AF1 & Ausência \\
AF2 & Presença \\
AF3 & Presença \\
AF4 & Presença \\
AF5 & Presença \\
\hline
\end{tabular}

Nota: Amostras com números antecedidos pelas letras $\mathrm{BD}$ referem-se aos pontos de coleta do rio Brandão, amostras com números antecedidos pelas letras $\mathrm{AF}$ referem-se aos pontos de coleta do córrego Águas Frias

A presença de E . coli foi confirmada em quatro pontos do córrego Á guas F rias, não sendo detectada em nenhum dos três pontos analisados do rio Brandão. $\mathrm{A}$ não detecção do microrganismo talvez possa ter correlação com a alta contagem de microrganismos heterotróficos apresentada nos pontos amostrados do Rio Brandão. D iante dos resultados apresentados nos testes bioquímicos para identificação de E . coli , é possível inferir sobre a contaminação de natureza fecal desta água. 


\section{Considerações Finais}

Com base nos resultados obtidos, foi demonstrado que a água dos rios no interior da A RIE Floresta da C icuta vem sofrendo despejos de efluentes ao longo do seu curso, chegando a seu interior com uma considerável carga de poluição. E sse fato a torna imprópria para a dessedentação de animais, manutenção do equilíbrio ecológico e conservação de comunidades aquáticas.

As águas desses rios são impróprias para os diversos fins de utilização para 0 homem, evidenciando alto grau de degradação.

Ressalta-se a necessidade de realização de ações voltadas para a Educação A mbiental, mostrando a importância da preservação dos corpos hídricos e destinação correta de resíduos. M edidas devem ser adotadas por meio de políticas públicas das cidades para tratamento de esgotos, e que, assim não sejam lançados nos rios sem 0 devido tratamento. Por fim, salienta-se também a importância do monitoramento frequente da qualidade da água nesta U nidade de C onservação.

\section{Referências}

AMARAL, L. A .; NADER FILHO, A .; ROSSI JUNIOR, O. D .; FERREIRA, F. L. A.; BA RROS, L. S. S. Á gua de consumo humano como fator de risco à saúde em propriedades rurais. Revista de Saúde Pública, v. 37, n. 4, p. 510-514, 2003.

A N D RE O LI, C. V. et al. L imites ao D esenvolvimento da R egião M etropolitana de Curitiba, Impostos pela E scassez de Água. In: SIM PÓ SIO BRASILEIRO DE EN GEN H ARIA SA N ITÁ RIA E AM BIENTAL, 9,2000, Porto Seguro-BA. A nais. Porto Seguro-BA : A BES, 2000. p.185-195.

BRA SIL. M inistério da Saúde. PORT AR IA no 1469, de 29 de dezembro de 2000. E stabelece os procedimentos e responsabilidades relativos ao controle e vigilância da qualidade da água para consumo humano e seu padrão de potabilidade, e dá outras providências. D iário O ficial da União. B rasilia, 2 de janeiro de 2001.

BRA SIL . M inistério do M eio A mbiente. Plano de manejo AR IE F loresta da Cicuta. V olta R edonda, 2016, 103 p. 
BRA SI L . R esolução C ON AM A n. 357, de 17 de março de 2005. C lassificação dos corposd' água e diretrizes ambientais para o seu enquadramento, bem como estabelece as condições e padrões de lançamento de efluentes. D isponível em বhttp://www.mma.gov.br/port/conama/ A cesso em: 07/06/2017.

CUNHA, A. H .; TART LER, N. S.; SANTOS, R. B.; FORTUNA, J.L .; A nálise microbiológica da água do rio Itanhém em T eixeira de Freitas BA. R evista Biocências, UNITAU, v. 16, n. 2, 2010.

FIL H O , A . F .; DIAS, M . F. F. Q ualidade microbiológica de águas minerais em galões de 20 litros. Alimentação e N utrição, A raraquara, v. 19, n. 3, p. 243-248, 2008.

MONSORES, D. W.;BUSTAM ANTE, J.G.G.;FEDULLO,L.P.L.; G O UVE IA , M . T. J. R elato da situação ambiental com vistas à preservação da área da F loresta da Cicuta. Relatório técnico, 1982, $17 \mathrm{p}$.

PAULA, S. M .; RAMIRES, I.; DANTAS, F. G.S.; TEODÓSIO, T. K.C.; CAM POS, K. B. G .; BRABES, K. C. S.; N EGRÃ O , F. J.; Q ualidade da Á gua do Rio D ourados, M S - Parâmetros Físico-Q uímicos e M icrobiológicos. E vidênda, Joaçaba, $v$. 13, n. 2, p. 83-100, jul./dez. 2013.

ROCHA, C. F. D.; BERGALLO,H. G .; ALVES, M . A. S.; SLUYS, M . V.A biodiversidade nos grandes remanescentes florestais do $E$ stado do $R$ io de $J$ aneiro enas restingas da M ata Atlântica. São Carlos: RiM A , 2003, 160 p.

SHIBATA, T .; SOLO-GABRIELE, H . M .; FLEM ING L. E.; ELMIR, S. $M$ onitoring marine recreational water quality using multiple microbial indicators in an urban tropical environment. Water R esearch, v.38, p.3119-3131, 2004.

SILVA, N.; JUN QUEIRA, V. C. A.; SILVEIRA, N. F. A.; TAN IW AKI, M .H .; SA NTOS, R.F.S.; GOM ES, R.A.R. M anual de métodos de análise microbiológica de alimentos. São Paulo :L ivraria V arela, 2010. 632p.

TO RRES, J. L. R. et al. M orfometria e qualidade da água da microbacia do ribeirão da Vida em U beraba-M G. G lobal Science and T echnology. v. 2, n. 1. p. 1-9, 2009. 